\title{
АКТУАЛЬНЫЕ ВОПРОСЫ РОССИЙСКОГО ГРАЖДАНСКОГО ЗАКОНОДАТЕЛЬСТВА ОХРАНЫ ПРАВ НА ГРАФФИТИ КАК ПРОИЗВЕДЕНИЙ ИЗОБРАЗИТЕЛЬНОГО ИСКУССТВА
}

Аннотация: Автор анализирует правовой статус и имеющчеся научные точки зрения о «граффити» (от итал. graffitoнацарапанный), под которыми понимают уличные рисунки, сделаннье на стенах домов, асфальте и других твердых поверхностях (например, вагонах). исследуются гражданско-правовые и административно-правовые аспекты данного феномена. Приводятся примеры правого регулирования граффити на национальном и региональном уровне. Исследуются примеры зарубежного опьта правового регулирования граффити. рассматриваются различные видь граффити. Рассматриваются фактические и правовые проблемы связанные с данным видом искусства. Историко-правовой и теоретический анализ статуса граффити выявил необходимость не только разработать определение данного вида «произведений уличного искусства», но и сформулировать критерии их классификации с тем, чтобь «ввести в рамки закона» творческую деятельность «уличных» художников. Автор разработал гражданско-правовое понятие граффити и предлагает определять их как произведения изобразительного искусства, выраженное на вещах, доступных для публичного обозрения, которое не нарушает права собственника вещей, не противоречит общественным интересам, принцииам гуманности и морали. Так же аргументируется мнение, что цель граффити может быть обусловлена публичным интересом (призыв к патриотическим поступкам, благотворительности и т.п.) или иметь частныйхарактер (привлечение внимания к объекту рекламирования и др.). Такие граффити должнь признаваться объектом интеллектуальной деятельности, а их авторы - иметь соответствующие права. В статье представлена авторская позиция о надписях и рисунках, сделанных в публичных местах и противоречащих принципам нравственности и морали.

Abstract: The author analyzes the legal status and current scientific points of view on "graffiti" (from Italian graffiato - "scratched"), which is how the street drawings made on the walls, asphalt, and other surfaces (such as train cars, etc.) are being considered. The civil-legal and administrative-legal aspects of this phenomenon are being researched. Examples are offered on the legal regulation of graffiti on the national and regional levels. The article examines the cases of foreign experience on the legal regulation of graffiti. Various forms of graffiti are being reviewed, as well as factual and legal problems associated with this form of art. The historical-legal and theoretical analyses have revealed the need to not only develop the definition of this form of "work of street art", but to also formulate the criteria of their classification in order to "enact into the framework of law" the creative work of "street" artists. The author has developed a civil legal concept of graffiti and proposes to define it as a work of visual art that is expressed on the objects accessible for public viewing, which does not violate the rights of the objects' owners, and does not contradict with the public interest and principles of humanity and morals. There is also an opinion that the purpose of graffiti can be justified by public interest (call to patriotic acts, charity, etc.), or have a private character (attracting attention to an object of advertising, etc.). Such graffiti should be considered an object of intellectual work and therefore, their authors should have the corresponding rights. Ключевье слова: Граффити, стрит-арт, уличные рисунки, гражданское право, авторское право, вандальные надписи, несанкционированные граффити, изобразительное искусство, закодированный текст, символика.

Keywords: Graffiti, street art, civil law, copyright law, vandalism, unsanctioned graffiti, visual arts, encrypted text, symbolism.

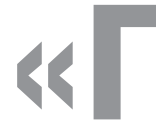

раффити» (от итал. graffito-нацарапанный) первоначально появилось в виде наскальных или настенных рисунков, «авторами» этих «произведений» были первобытные люди, которые пытались таким образом запечатлеть происходящие события реальной действительности и за неимением материалов использовали скалы и камни, выцарапывая ими задуманный объект или сюжет (например, охоту на мамонта).

Позднее, несмотря на изобретение бумаги, керамики и других объектов, на которых можно сделать любой рисунок, стены и скалы по-прежнему используются в качестве «полотна». При этом менялись не только орудия труда художников (камни на краски), но и расширялся диапазон сюжетов - от простых изображений животных и людей до картин, отражающих важнейшие события жизни общества.

В ведущих странах мира со временем наряду с «граффити» стали использовать термин «стрит-арт», подразумевая под ним «уличное искусство», которое по своему содержанию «выше» граффити. Здесь работают стритрайтеры - настоящие художники (к при- 


\section{Право и политика 1 (181) • 2015}

меру, можно вспомнить таких авторитетов как Баския, Бэнкси, Шепард Фейри) цели их деятельности разные, но объединяет творческий характер работ. Хотя многие их «полотна» - явное подражание Энди Уорхолу. Впрочем, подражание, как и в любом уважающем себя постмодернистском жанре, не считается зазорным. Стритрайтеры подшучивают над рекламой и множат сюжеты из сокровищницы мирового искусства от Ноя до Микки-Мауса и Обамы ${ }^{1}$.

Россия не осталась в стороне от новых веяний «запада». К примеру, в соответствии с Государственной программой города Москвы «Культура Москвы на 2012-2018 годы» в рамках общегородского фестиваля «Лучший город Земли» проведен «Граффитифестиваль», который позволил привлечь уличных художников к изменению облика города Москвы. Кроме того, был разработан сайт в сети Интернет http:// lgz-moscow.ru, где любой житель города мог оставить заявку на создание граффити-объекта в определенном месте Москвы. По итогам данного проекта летом 2013 года в Москве было создано 150 объектов уличного искусства, в том числе была разрисована стена сборочного цеха автозавода «Москвич», площадью почти в 10 тысяч квадратных метров. Эта «картина» занесена в российскую Книгу рекордов Гиннеса ${ }^{2}$.

В г. Кострома регулярно проводится молодежный фестиваль «СритВэй», в котором активно участвуют граффитчи, создающие в присутствии зрителей свои «полотна». Эти мероприятия проводятся по инициативе и при активном участии администрациигорода ${ }^{3}$.

Такие направления в использовании «уличных» рисунков приветствуются и изучаются как различные виды социальной деятельности, в том числе на уровне диссертаций. В качестве примера можно назвать работы А.Ю. Ларионовой ${ }^{4}$, Т.С. Стрелковой ${ }^{5}$,

\footnotetext{
${ }^{1}$ http://www.art-top.ru/modern_art/street_art.html

${ }^{2}$ Постановление Правительства Москвы от 20.09.2011 № 431-ПП (ред. от 18.07.2014) «Об утверждении Государственной программы города Москвы «Культура Москвы на 2012-2018 год» [электрон. ресурс] // СПС КонсультантПлюс.

${ }^{3}$ См., например, протокол пленарного совещания при Главе города Костромы от 25 октября 2010г. №2 [Электронный ресурс] // СПС Консультант Плюс.

4 Ларионова А.Ю. Неформальный студенческий дискурс: социолингвистический и лингвокультурологический аспекты (на материале граффити) // Дисс. . . доктора филолог. . . наук. Екатеринбург. 2011.- 552 с.

${ }^{5}$ Стрелкова Т.С. Социально-педагогические особенности возникновения, развития и функционирования подростково-молодежных граффити // Дисс. . . канд. . . . педагог. наук Коломна, 2007. - 213 с.
}

Н.И. Тюкаевой6. В этих и других исследованиях граффити рассматриваются как источник различных проявлений личности (социальных, психологических и др.). Некоторые авторы изучают граффити с точки зрения истории, поскольку в них могут содержаться важные сведения прошлого, культуры, письменности; анализируются местонахождение надписей и рисунков, социальная принадлежность «авторов», проводятся классификации граффити по тематическим группам, назначению надписей и рисунков и т.п. Российские психологи исследуют граффити как средство конструирования социокультурной реальности.

Монография О.П.Медведевой «Искусство граффити» п посвящена современному «уличному» искусству создания художественных композиций и надписей на любых поверхностях, как-то: забор, стена, гараж и т.д. с помощью аэрозольных баллончиков.

Однако с точки зрения гражданского права России, «уличные рисунки» (граффити или стрит-арт ${ }^{8}$ ) не являются объектом правовой охраны, а потому отечественные цивилисты не уделяют им должного внимания. Именно этим обстоятельством следует объяснить факт - тема «граффити» в современной юридической литературе анализируется крайне редко, точнее сказать, она практически не исследована.

Тем не менее, граффити не просто существует как самостоятельный вид творчества, но и активно используется практически во всех странах мира: в любом населенном пункте можно увидеть рисунки «местных и заезжих художников», которые, кстати сказать, нередко носят явно агрессивный характер. В частности, Л.В. Арефьева и Г.А. Магомедов отмечают: «С недавнего времени проявления «языка вражды» начали «выплескиваться» непосредственно на улицы городов и поселков в виде уличных граффити, надписей на стенах домов, гаражей, ларьков, заборах, на транспорте и т.п. И присуща эта проблема не только России. В англоязычных странах для обозначения этой проблемы используется устойчивый термин hate speech - «разжигание ненависти»»".

\footnotetext{
${ }^{6}$ Тюкаева Н.И. Студенческое граффити как жанр естественной письменной русской речи // Дисс. ... канд. филол. Наук. Барнаул., 2005.- 229 c.

${ }^{7}$ Медведева О.П. Искусство граффити. Ростов-на-Дону. Феникс, 2005.

${ }^{8}$ В этой статье данные термины будут употребляться как синонимы, хотя автор допускает возможность их частичного различия, об этом будет сказано ниже.

${ }^{9}$ Арефьева Л.В., Магомедов Г.А. Проблема разжигания национальной и религиозной нетерпимости в современных СМИ //
} 
Городские и сельские органы местного самоуправления вынуждены учитывать этот факт и в зависимости от содержания граффити принимать соответствующие меры. Скажем, Свердловский областной суд признал законным привлечение к административной ответственности ФГАОУ ВПО «Университет» (название условное) за неисполнение обязанности по содержанию фасада здания принадлежащей ему трансформаторной подстанции, выразившейся в неудалении вандальных надписей (граффити) на указанной стене, сделанных неустановленными лицами. Суд отметил, что вышеуказанный факт обоснованно зафиксирован в протоколе об административном правонарушении, содержание и оформление которого соответствуют предъявляемым требованиям и подтверждены приложенными к нему фототаблицами ${ }^{10}$.

Кроме того, как показывает практика, уличные художники в нарушение установленных запретов «расписывают» промышленные объекты, которые затем нуждаются в ремонте. Так, ФАС Западно-сибирского округа признал повреждение лакокрасочного слоя котлов вагонов (цистерн) вследствие нанесения рисунков «граффити» и непригодность этих вагонов под налив в связи с необходимостью полной покраски котлов для восстановления знаков опасности ${ }^{11}$.

Степень распространения подобных «художеств» на различных видах транспорта такова, что подготовлен и внесен в ГД ФС РФ проект изменений статьи 11.15 . «Повреждение имущества на транспортных средствах общего пользования, грузовых вагонов или иного предназначенного для перевозки и хранения грузов на транспорте оборудования» Кодекса об административных правонарушениях Российской Федерации ${ }^{12}$.

Перечень использования граффити как в положительных так и негативных целях можно продолжить, однако, и приведенных фактов, по моему мнению, достаточно, чтобы признать необходимость квалифицировать «граффити» как гражданско-правовое явление, которому следует придать юридический статус.

В первую очередь хотелось бы обратиться к вопросу о понятии «граффити» в российском законодательстве.

«Российский следователь». 2012. № 19 [электрон. ресурс] // СПС КонсультантПлюс.

${ }^{10}$ Постановление заместителя председателя Свердловского областного суда от 17 февраля 2014 г. № 4a-209/2014[электрон. ресурс] // СПС КонсультантПлюс.

${ }^{11}$ Постановление ФАС Западно-Сибирского округа признал от 28 ноября 2012 г. по делу № A45-12392/2012

${ }^{12}$ Проект Федерального закона N 214900-6 «О внесении изменений в Кодекс Российской Федерации об административных правонарушениях» [электрон. ресурс] // СПС КонсультантПлюс.
На уровне федеральных законов граффити не регулируется и, соответственно, его содержание не раскрывается. В то же время федеральным законодательством предусмотрено несколько составов правонарушений, по которым возможно привлечение к ответственности за создание надписей или иных изображений, носящих противоправный характер или портящих имущество. В частности, можно назвать ст. 213 Уголовного кодекса РФ (УК РФ) «Хулиганство»; ст. 214 УК РФ - «Вандализм»; ст. 7.17 КоАП ${ }^{13}$ РФ «Уничтожение или повреждение чужого имущества»; ст. 20.1 КоАП РФ «Мелкое хулиганство»; ст. 20.3 КоАП РФ «Пропаганда или публичное демонстрирование нацистской атрибутики или символики». Обратим внимание, термин «граффити» в этих документах не употребляется, хотя участники судебных разбирательств используют именно это понятие.

Вместе с тем есть несколько нормативных правовых документов субъектов РФ, в которых граффити прямо упоминаются. Так, Правительство Москвы определило: использовать аэрогидродинамические (АГД) технологии для очистки фасадов от природных (плесени, грибка), атмосферных, грязепочвенных, нефтяных и искусственных загрязнений (например, типа «граффити») $)^{14}$ (курсив автора).

Статья 19 Закона «Об административных правонарушениях в Санкт-Петербурге» устанавливает ответственность за самовольное нанесение надписей и графических изображений (граффити) в виде предупреждения или административного штрафа на граждан в размере от одной тысячи до четырех тысяч рублей; на должностных лиц - от трех тысяч до десяти тысяч рублей; на юридических лиц - от двадцати тысяч до ста тысяч рублей ${ }^{15}$ (курсив автора). Аналогичное определение граффити содержится и в Постановлении Правительства СанктПетербурга от 16 ноября 2007 года № 1334 «Об утверждении Правил уборки, обеспечения чистоты и порядка на территории Санкт-Петербурга ${ }^{16} »$.

\footnotetext{
${ }^{13}$ Кодекс Российской Федерации об административных правонарушениях: закон Российской Федерации от 30 декабря 2001 г. № 195 - Ф3] // Собрание законодательства РФ. 2002. 7 января.

${ }^{14}$ Постановление Правительства Москвы от 31.07.2007 N 651-ПП (ред. от 28.03.2012) «Об утверждении норматива города Москвы «Содержание и ремонт фасадов зданий и сооружений»// «Вестник Мэра и Правительства Москвы». 29.08.2007. № 48.

15 Закон СПб от 31 мая 2010 г. № 273-70 «Об административных правонарушениях в Санкт-Петербурге» // Петербургский дневник. 2010. 14 июня.

${ }^{16}$ Постановление Правительства Санкт-Петербурга от 16 ноября 2007 г., № 1334 «Об утверждении Правил уборки, обеспечения чистоты и порядка на территории Санкт-Петербурга» [Электронный ресурс] // СПС Консультант Плюс.
} 


\section{Право и политика 1 (181) • 2015}

На основании этих примеров можно сделать вывод, что органы власти субъектов РФ рассматривают несанкционированные граффити как правонарушения, несмотря на то, что они могут оказывать и положительное социальное воздействие.

Вышеизложенное убедительно свидетельствует о необходимости исследования граффити с точки зрения гражданского права и формирования соответствующей нормативной правовой базы на уровне РФ с тем, чтобы «ввести в рамки закона» деятельность тех лиц, которые делают надписи и создают рисунки, имеющие положительную социальную направленность.

В этой связи представляет интерес мнение некоторых авторов о соотношении «граффити» и «стрит-арт». К примеру, высказана точка зрения о том, что граффити и стрит-арт существуют как зло и добро параллельно, имея принципиальные отличия. Граффити - всегда несанкционированное, исключительно хулиганское проявление не столько творческих эмоций, сколько примитивности и абсолютного неуважения к людям. В то время как стрит-арт несет в себе положительные социальные функции, не конфликтует с законом ${ }^{17}$. Иного мнения на граффити придерживается украинский ученый Инна Головаха. Она приводит убедительные аргументы, что «граффити» - это прежде всего закодированный текст, символика которого отражает определенные события культурной, политической или общественной жизни социума, членами которого являются его исполнители ${ }^{18}$.

Психодинамическое значение граффити состоит в том, что в силу своей анонимности настенные рисунки и надписи являются способом выражения внутреннего состояния «автора», которое может иметь и агрессию, подавляемую субъектом из-за опасности привлечения к ответственности.

Наконец, высказано суждение, что граффити - вид уличного искусства, одна из самых актуальных форм художественного самовыражения по всему миру. Существует множество разных стилей и видов граффити. Произведения, создаваемые граффити-художниками, - самостоятельный жанр современного искусства, неотъемлемая часть культуры и городского образа жизни. Во многих странах и городах есть свои известные райтеры, создающие на улицах города настоящие шедевры. К «граффити» следует отнести любой вид уличного

\footnotetext{
${ }^{17}$ Борьба с граффити. Антивандальные покрытия силокор антиграффити [Электронный ресурc] http://www.npostrim.ru/antigraffiti.htm

${ }^{18}$ Головаха И.В. Социальное значение асоциальных граффити (Бытование и функции современных киевских граффити) // Социология: теория, методы, маркетинг. 2004. № 2. С. 65.
}

раскрашивания стен, на которых можно найти все: от простых написанных слов до изысканных рисунков ${ }^{19}$.

Сторонники вышеизложенной точки зрения классифицируют граффити по различным критериям. Например, в зависимости от места расположения граффити могут быть активными или пассивными. К первым относят надписи и рисунки, сделанные, как правило, на внешних сторонах зданий, сооружений, в местах большого скопления людей (метро, стадион и т.п.). Вторые - размещаются внутри зданий. Это граффити в кинотеатрах, туалетах, на столах и т.п.

В зависимости от наличия официального разрешения или его отсутствия - граффити можно разделить на законные и незаконные. Так, граффити, сделанные на основании заказа, конкурса, или иного предусмотренного нормативным правовым актом основания, будут отнесены к первой группе. Незаконные граффити делаются по инициативе «автора», без согласия соответствующих лиц, нарушают законодательство, портя чужое имущество.

По субъектному составу граффити можно классифицировать на единоличные и коллективные.

С точки зрения гражданского права, «граффити» - произведение (изображение, рисунок, надпись), написанное или нарисованное физическими лицами на вещах, в том числе недвижимых. В России граффити не является охраняемым результатом интеллектуальной деятельности. Более того, как показывает практика, создатели граффити из-за опасности быть привлеченными к ответственности «за порчу чужого имущества» не оставляют «следов» своего авторства.

Вместе с тем, известны многочисленные случаи, когда граффити создаются по заказу собственников или арендаторов зданий, сооружений и авторы известны. Чаще всего такие работы осуществляют в целях рекламы (к примеру, на стене парикмахерской изображается девушка с оригинальной прической и ярким маникюром). Однако в связи с тем, что права на такие произведения не охраняются, создатели, получая вознаграждение по договору возмездного выполнения работ (подряд), не обладают интеллектуальными правами на граффити.

С нашей точки зрения, граффити как вид творческой деятельности нуждается в научном анализе,

\footnotetext{
${ }^{19}$ Жизнь в каждойлинии граффити [Электронный ресурс]/http://itstep. wordpress.com $/ 2010 / 05 / 12 / \% \mathrm{D} 0 \% \mathrm{~B} 6 \% \mathrm{D} 0 \% \mathrm{~B} 8 \% \mathrm{D} 0 \% \mathrm{~B} 7 \% \mathrm{D} 0 \% \mathrm{BD} \%$ D1\%8C-\%D0\%B2-\%D0\%BA\%D0\%B0\%D0\%B6\%D0\%B4\%D0\% BE\%D0\%B9-\%D0\%BB\%D0\%B8\%D0\%BD\%D0\%B8\%D0\%B8$\%$ D $0 \%$ B $3 \%$ D $1 \%$ \% $\% \mathrm{D} 1 \% 84 \% \mathrm{D} 0 \% \mathrm{~B} 8 \% \mathrm{D} 1 \% 82 \% \mathrm{D} 0 \% \mathrm{~B} 8 /$
} 
результаты которого могут быть использованы в законотворческом процессе. В этой связи предлагаем авторское определение:

- $\quad$ граффити - произведение изобразительного искусства, выраженное на вещах, доступных для публичного обозрения, которое не нарушает права собственника вещей, не противоречит общественным интересам, принципам гуманности и морали;

- цель граффити может быть обусловлена публичным интересом (призыв к патриотическим поступкам, благотворительности и т.п.) или иметь частный характер (привлечение внимания к объекту рекламирования, формирование или поддержание интереса к нему, продвижение на рынке и др.);

- способ создания граффити (посредством использования краски, мела иного материала, в том числе природного) не имеет правого значения;

Легко смываемые или стираемые граффити должны быть зафиксированы в виде фотографии, слайда и т.п.

У автора граффити отсутствует право отказаться от обнародования созданного им произведения изобразительного искусства, поскольку граффити всегда является обнародованным уже в момент его создания в силу нахождения вещи, на которой оно изображено, в доступных для публичного обозрения местах. Аналогичной точки зрения придерживается В.А. Удалкин, в частности, он пишет: » . . . существуют произведения, право на обнародование которых осуществляется одновременно с их созданием (например, лекции, музыкальные импровизации). Группа таких произведений имеется в изобразительном искусстве. Условно такую группу произведений можно назвать произведениями «уличного» изобразительного искусства. К ним могут быть отнесены, прежде всего, граффити, ледяные и песочные фигуры, отдельные произведения садово-паркового искусства, которые имеют преимущественно изобразительные, а не декоративные черты». ${ }^{20}$
Особого внимания заслуживают изображения на асфальте. Как показывает практика, такие граффити чаще всего делаются в рекламных целях. Так, английский художник Джулиан Бивер, рекламируя рисунками мелом на тротуарах товары популярных производителей от компьютеров Sony и автомобилей BMW до напитка Coca-Cola и Slate, стал известным.

Однако не все надписи на асфальте или других объектах, находящихся в публичных местах, имеют статус граффити. Так, Е.А. Свиридова приходит к выводу, что изображения, представляющие собой самостоятельный результат творческой деятельности можно назвать рекламой. При этом такое изображение будет одновременно являться объектом авторского права (произведением изобразительного искусства). В то же время обычную надпись, не обладающую новизной и оригинальностью (например, «косметолог, тел.: 00-00-00»), следует рассматривать как указатель, не содержащий элементов творчества ${ }^{21}$.

Думаю, что эту позицию следует признать правильной и поддержать. Что же касается изображений (надписей, рисунков и пр.), носящих противоправный, агрессивный характер, противоречащих общественным интересам, принципам гуманности и морали, то, вне всякого сомнения, таки «художества» следует уничтожать, а их «авторов» привлекать к соответствующему виду ответственности. С точки зрения гражданского законодательства права на такие изображения не возникают, а сами эти изображения следует квалифицировать как «квази-граффити».

С учетом изложенного, полагаю, что настало время дополнить главу 70 ГК РФ «Авторское право» новой статьей «Граффити», содержание которой построить по аналогии с другими объектами авторского права.

Таковы некоторые актуальные правовые вопросы российского законодательства в правовой системе охраны граффити как произведений изобразительного искусства.

\section{Библиография:}

1. Кодекс Российской Федерации об административных правонарушениях от 30.12.2001 № 195-Ф3 (ред. от 22.10.2014) (с изм. и доп., вступ. в силу с 22.01.2015) http://www.pravo.gov.ru-23.10.2014.

2. Закон СПб от 31 мая 2010 г. № 273-70 «Об административных правонарушениях в Санкт-Петербурге» // Петербургский дневник. 2010. 14 июня.

3. Постановление Правительства Москвы от 20.09.2011 № 431-ПП (ред. от 18.07.2014) «Об утверждении Государственной программы города Москвы «Культура Москвы на 2012-2018 год» [электрон. ресурс] // СПС КонсультантПлюс.

4. Постановление Правительства Москвы от 31.07.2007 N 651-ПП (ред. от 28.03.2012) «Об утверждении норматива города Москвы «Содержание и ремонт фасадов зданий и сооружений»/// «Вестник Мэра и Правительства Москвы». 29.08.2007. № 48.

${ }^{20}$ Удалкин В.А. Право на обнародование произведения // «Право и экономика». 2009. № 7 [электрон. ресурс] // СПС КонсультантПлюс

\footnotetext{
${ }^{21}$ Свиридова Е.А. Реклама как объект интеллектуальной собственности: правовой аспект: Монография. - «ЮРКОМПАНИ». 2013 [электрон. ресурс] // СПС КонсультантПлюс.
} 
DOI: $10.7256 / 1811-9018.2015 .1 .13667$

При цитировании этой статьи сноска на dоі обязательна

\section{Право и политика 1 (181) 2015}

5. Протокол пленарного совещания при Главе города Костромы от 25 октября 2010г. №2 [Электронный ресурс] // СПС Консультант Плюс.

6. Постановление заместителя председателя Свердловского областного суда от 17 февраля 2014 г. № 4a-209/2014[электрон. ресурс] // СПС КонсультантПлюс.

7. Постановление ФАС Западно-Сибирского округа признал от 28 ноября 2012 г. по делу № А45-12392/2012

8. Проект Федерального закона N 214900-6 «О внесении изменений в Кодекс Российской Федерации об административных правонарушениях» [электрон. ресурс] // СПС КонсультантПлюс.

9. Арефьева Л.В., Магомедов Г.А. Проблема разжигания национальной и религиозной нетерпимости в современных СМИ // «Российский следователь». 2012. № 19 [электрон. ресурс] // СПС КонсультантПлюс. Борьба с граффити. Антивандальные покрытия силокор антиграффити [Электронный ресурс] http://www.npostrim.ru/antigraffiti.htm

10. Головаха И. В. Социальное значение асоциальных граффити. (Бытование и функции современных киевских граффити) / И. В. Головаха // Социология: теория, методы, маркетинг. 2004. № 2. С. $12-18$.

11. Граффити: искусство или вандализм? [Электронный ресурс] / www.graffitimarket.ru.

12. Жизнь в каждой линии граффити [Электронный ресурc] / http://itstep.wordpress.com/2010/05/12/\%D0\%B6 $\%$ D0\%B8\%D0\%B7\%D0\%BD \%D1\%8C-\%D0\%B2-\%D0\%BA\%D0\%B0\%D0\%B6\%D0\%B4\%D0\%BE\%D0\%B9$\% \mathrm{D} 0 \% \mathrm{BB} \% \mathrm{D} 0 \% \mathrm{~B} 8 \% \mathrm{D} 0 \% \mathrm{BD} \% \mathrm{D} 0 \% \mathrm{~B} 8 \% \mathrm{D} 0 \% \mathrm{~B} 8-\% \mathrm{D} 0 \% \mathrm{~B} 3 \% \mathrm{D} 1 \% 80 \% \mathrm{D} 0 \% \mathrm{~B} 0 \% \mathrm{D} 1 \% 84 \% \mathrm{D} 1 \% 84 \% \mathrm{D} 0 \% \mathrm{~B} 8 \% \mathrm{D} 1 \% 82 \% \mathrm{D} 0 \% \mathrm{~B} 8 /$

13. Ларионова А.Ю. Неформальный студенческий дискурс: социолингвистический и лингвокультурологический аспекты (на материале граффити) // Дисс. . . доктора филолог. . . наук. Екатеринбург. 2011.-552 с.

14. Медведева О. П. Искусство граффити-Ростов-на-Дону: Феникс, 2005.

15. Свиридова Е. А. Реклама на асфальте: правовой аспект / Е. А. Свиридова // Образование и право. 2011. № 10. С. $22-27$.

16. Стрелкова Т.С. Социально-педагогические особенности возникновения, развития и функционирования подростковомолодежных граффити // Дисс. . . канд. . . . педагог. наук Коломна, 2007.-213 с.

17. Тюкаева Н.И. Студенческое граффити как жанр естественной письменной русской речи // Дисс. ... канд. филол. Наук. Барнаул., 2005.-229 с.

18. Удалкин В.А. Право на обнародование произведения // «Право и экономика». 2009. № 7 [электрон. ресурс] // СПС КонсультантПлюс

19. Раскотиков И.С. Гражданское законодательство как инструмент защиты публичных и частных интересов // Право и политика. - 2014. - 5. - С. 601 - 611. DOI: 10.7256/1811-9018.2014.5.11714.

\section{References (transliterated):}

1. Aref'eva L.V., Magomedov G.A. Problema razzhiganiya natsional'noi i religioznoi neterpimosti v sovremennykh SMI // «Rossiiskii sledovatel'». 2012. № 19 [elektron. resurs] // SPS Konsul’tantPlyus. Bor’ba s graffiti. Antivandal'nye pokrytiya silokor antigraffiti [Elektronnyi resurs] http://www.npostrim.ru/antigraffiti.htm

2. Golovakha I. V. Sotsial'noe znachenie asotsial'nykh graffiti. (Bytovanie i funktsii sovremennykh kievskikh graffiti) / I. V. Golovakha // Sotsiologiya: teoriya, metody, marketing. 2004. № 2. S. 12 - 18.

3. Larionova A.Yu. Neformal'nyi studencheskii diskurs: sotsiolingvisticheskii i lingvokul'turologicheskii aspekty (na materiale graffiti) // Diss. . . doktora filolog. . nauk. Ekaterinburg. 2011.-552 s.

4. Medvedeva O. P. Iskusstvo graffiti-Rostov-na-Donu: Feniks, 2005.

5. Sviridova E. A. Reklama na asfal’te: pravovoi aspekt / E. A. Sviridova // Obrazovanie i pravo. 2011. № 10. S. $22-27$.

6. Strelkova T.S. Sotsial'no-pedagogicheskie osobennosti vozniknoveniya, razvitiya i funktsionirovaniya podrostkovo-molodezhnykh graffiti // Diss. . kand. . . . pedagog. nauk Kolomna, 2007.-213 s.

7. Tyukaeva N.I. Studencheskoe graffiti kak zhanr estestvennoi pis'mennoi russkoi rechi // Diss. ... kand. filol. Nauk. Barnaul., 2005.-229 c.

8. Udalkin V.A. Pravo na obnarodovanie proizvedeniya // «Pravo i ekonomika». 2009. № 7 [elektron. resurs] // SPS Konsul’tantPlyus

9. Raskotikov I.S. Grazhdanskoe zakonodatel'stvo kak instrument zashchity publichnykh i chastnykh interesov // Pravo i politika. - 2014. - 5. - C. 601 - 611. DOI: 10.7256/1811-9018.2014.5.11714. 